\title{
Bacteroides fragilis toxin 2 damages human colonic mucosa in vitro
}

M Riegler, M Lotz, C Sears, C Pothoulakis, I Castagliuolo, C C Wang, R Sedivy, T Sogukoglu, E Cosentini, G Bischof, W Feil, B Teleky, G Hamilton, J T LaMont, E Wenzl

University Clinic of Surgery, University of Vienna, Austria T Sogukoglu E Cosentini

G Bischof

B Teleky

G Hamilton

E Wenzl

Institute of Clinical Pathology, University of Vienna, Austria R Sedivy

Department of Surgery, Danube Hospital, Vienna, Austria

W Feil

Division of

Gastroenterology, Beth Israel Deaconess Medical Centre, Boston, Harvard Medical School, Massachusetts, USA

M Riegler

M Lotz

C Pothoulakis

I Castagliuolo

C C Wang

J T LaMont

Divisions of Infectious Diseases and

Gastroenterology, John Hopkins University, Baltimore, Maryland, USA

C Sears

Correspondence to: Dr C Pothoulakis, Division of Gastroenterology, Beth Israel Deaconess Medical Centre, 330 Brookline Ave, Boston, MA 02215, USA.

Accepted for publication 27 October 1998

\begin{abstract}
Background-Strains of Bacteroides fragilis producing a $20 \mathrm{kDa}$ protein toxin (B fragilis toxin (BFT) or fragilysin) are associated with diarrhoea in animals and humans. Although in vitro results indicate that BFT damages intestinal epithelial cells in culture, the effects of BFT on native human colon are not known.

Aims-To examine the electrophysiological and morphological effects of purified BFT-2 on human colonic mucosa in vitro. Methods-For resistance (R) measurements, colonic mucosa mounted in Ussing chambers was exposed to luminal or serosal BFT-2 (1.25-10 $\mathrm{nM})$ and after four hours morphological damage was measured on haematoxylin and eosin stained sections using morphometry. F actin distribution was assessed using confocal microscopy.

Results-Serosal BFT-2 for four hours was four-, two-, seven-, and threefold more potent than luminal BFT-2 in decreasing resistance, increasing epithelial ${ }^{3} \mathbf{H}-$ mannitol permeability, and damaging crypt and surface colonocytes, respectively $(p<0.05)$. Confocal microscopy showed reduced colonocyte $F$ actin staining intensity after exposure to BFT-2.

Conclusions-BFT-2 increases human colonic permeability and damages human colonic epithelial cells in vitro. These effects may be important in the development of diarrhoea and intestinal inflammation caused by $B$ fragilis in vivo.

(Gut 1999;44:504-510)
\end{abstract}

Keywords: B fragilis toxin; toxin mediated colonocyte damage; actin filaments; transepithelial resistance; morphometry

The Gram negative anaerobic rod Bacteroides fragilis is associated with diarrhoea in animals ${ }^{1-9}$ and humans. ${ }^{10-13}$ Culture supernatants of enterotoxigenic $B$ fragilis (ETBF) induce fluid secretion in calf, rabbit, and lamb ligated ileal loops, ${ }^{45}$ and ETBF causes fluid secretion and intestinal inflammation when administered orogastrically to newborn rabbits. ${ }^{8}$ Histological examination of ileal loops revealed that ETBF culture supernatants or microorganisms cause rounding and exfoliation of surface epithelial cells as well as mucosal inflammation. ${ }^{8914}$ Similar secretory and histological changes have been observed in rat, rab- bit, and lamb intestinal loops exposed to purified $B$ fragilis toxin $1 .^{15}$

Several studies suggest that the intestinal effects of $B$ fragilis are attributable to a $20 \mathrm{kDa}$ protein toxin. ${ }^{14-17}$ Two isoforms of $B$ fragilis toxin (BFT) have been isolated, one secreted by the lamb (ETBF strain VPI $13784^{14}{ }^{17}$ ), and the second by the piglet (ETBF strain 86-5443-2-2 ${ }^{16}$; see also Wu and Sears, unpublished observations). Nucleotide sequence analysis studies revealed an $92 \%$ identity and $95 \%$ similarity in the amino acid sequences of these two isoforms of $\mathrm{BFT}^{17}$ (see also Wu and Sears, unpublished observations). Based on their biochemical properties, these isoforms represent two distinct proteins and were therefore termed BFT-1 (strain VPI 13784) and BFT-2 (strain 86-5443-2-2). Although detailed cross comparison studies are not yet complete, the biological activities of these two proteins are similar ${ }^{16-23}$ (see also Wu and Sears, unpublished observations). In vitro studies using human colonic adenocarcinoma cell lines indicate that ETBF and their toxins alter the structure and function of colonic epithelial cells. For example, exposure of subconfluent Caco-2, HT 29/C1, or HT 29 cells to either ETBF culture supernatants ${ }^{18}{ }^{23}$ or purified toxins 1 or $2^{19-2123} 24$ causes cell rounding, swelling, and loss of cell to cell contacts. Furthermore, BFT-1 or BFT-2 also decrease transepithelial resistance when incubated with HT 29/C1, HT 29, T84, MDCK, or rat alveolar epithelial (type II) cell monolayers in vitro. ${ }^{1824} \mathrm{Al}-$ though a number of in vitro studies indicate that BFT-1 and BFT-2 affect the cell cytoskeleton of intestinal epithelial cells, ${ }^{17-21}{ }^{26}$ the net F actin content of HT 29/C1 cells is unchanged after BFT treatment. ${ }^{20}$

Based on the above considerations, the present study was designed to examine the effect of purified BFT-2 on electrophysiology and morphology of human colonic mucosal strips mounted in Ussing chambers.

\section{Methods}

TOXIN PREPARATION

Bacteroides fragilis toxin 2 (BFT-2) was purified from culture supernatant broth of enterotoxigenic $B$ fragilis $86-5443-2-2$ as previously described. ${ }^{14}{ }^{21}$ Purity of the toxin was assessed by analytical reverse phase fast protein liquid chromatography as previously described. ${ }^{21}$

Abbreviations used in this paper: BFT, Bacteroides fragilis toxin; ETBF, enterotoxigenic Bacteroides fragilis; Isc, short circuit current; PD, potential difference; R, resistance. 
Briefly, approximately $80 \mu \mathrm{g}$ BFT-2 was injected onto a RepRPC reverse phase column (Pharmacia Inc., Piscataway, New Jersey, USA) equilibrated with water and $0.05 \%$ trifluoroacetic acid. Protein was eluted with a $0-100 \%$ gradient of acetonitrile and $0.05 \%$ trifluoroacetic acid over two hours. Eluted protein was detected by ultraviolet absorption at $226 \mathrm{~nm}$. BFT-2 eluted as a single sharp peak at approximately $41 \%$ acetonitrile. Purified BFT-2 was maintained at $-70^{\circ} \mathrm{C}$ in a $0.05 \mathrm{M}$ Tris-0.18 M NaCl buffer ( $\mathrm{pH} 7.5$ ) until use. Biological activity of BFT-2 was tested using subconfluent HT 29/C1 monolayers (obtained from Daniel Louvard, Institute Pasteur, Paris, France) as previously described. ${ }^{21}$

EXPERIMENTAL DESIGN

Human colonic mucosal sheets were first equilibrated in Ussing chambers with buffer alone for 60 minutes as previously described. ${ }^{27}$ Serosal solution was then replaced with buffer containing 1.25-10 nM BFT-2 for four hours. In some experiments colonic tissues were incubated with luminal buffer containing $10 \mathrm{nM}$ BFT-2 for four hours. Control tissues were incubated with buffer alone for five hours.

USSING CHAMBER MEASUREMENTS

In this study 51 individual specimens of histological tumour-free rectosigmoid colon were used. After removal of the seromuscular layer by blunt dissection one to five mucosal sheets from each specimen measuring $4-10 \mathrm{~cm}^{2}$ were mounted in Ussing chambers (DCTSYS, Precision Instrument Design, California, USA; $1.03 \mathrm{~cm}^{2}$ surface area) as previously described. ${ }^{27-30}$ The luminal and serosal sides were bathed at $37^{\circ} \mathrm{C}$ with a nutrient buffer containing: $\mathrm{NaCl} 122.0 \mathrm{mM} / 1, \mathrm{CaCl}_{2} 2.0$ $\mathrm{mM} / 1, \mathrm{MgSO}_{4} 1.3 \mathrm{mM} / 1, \mathrm{KCl} 5.0 \mathrm{mM} / 1$, glucose $20.0 \mathrm{mM} / 1$, and $\mathrm{NaHCO}_{3} 25.0 \mathrm{mM} / 1$ $\left(\mathrm{pH} 7.4\right.$ when gassed with $95 \% \mathrm{O}_{2} / 5 \% \mathrm{CO}_{2}$ temperature $37^{\circ} \mathrm{C}$ ). The upper level of fluids in both luminal and serosal reservoirs was identical. Potential difference (PD) and short circuit current (Isc) were continuously measured and registered every 10 minutes as previously described. ${ }^{27}$ Luminal and serosal solutions were connected via $\mathrm{Ag}-\mathrm{AgCl}$ electrodes to a voltmeter (Model VCC600, Revision G, Voltage-Current Clamp, Physiologic Instruments, San Diego, California, USA). Resistance $(\mathrm{R})$ was calculated using Ohm's law from the open circuit PD and Isc. PD values were given in $\mathrm{mV}$ (lumen negative), Isc in $\mu \mathrm{A} / \mathrm{cm}^{2}$, and $\mathrm{R}$ in $\mathrm{Ohm} . \mathrm{cm}^{2}$. PD values were corrected for the junction potentials (less than $0.1 \mathrm{mV}$ ) between the luminal and serosal solutions. ${ }^{2} 30$

Epithelial permeability to ${ }^{3} \mathrm{H}$-mannitol was determined as previously described. ${ }^{27}$ Three human colonic explants from a single individual were mounted in Ussing chambers in parallel and incubated with either buffer alone or serosal or luminal buffer containing $10 \mathrm{nM}$ BFT-2 for four hours ( $\mathrm{n}=5$, paired tissues). After an equilibration period of 30 minutes, ${ }^{3} \mathrm{H}$-mannitol (26.4 Ci/mmol; Dupont-New England Nuclear, Boston, Massachusetts, USA) was added to $8 \mathrm{ml}$ serosal buffer at a final concentration of $0.32 \mathrm{nM}$. Luminal aliquots of $200 \mu \mathrm{l}$ were taken for liquid scintillation counting using $5 \mathrm{ml}$ Quicksave A scintillation fluid (Zinser, Maidenhead, UK) and replaced with $200 \mu \mathrm{l}$ buffer to eliminate a transepithelial solute gradient. The radioactivity of ${ }^{3} \mathrm{H}$-mannitol in the luminal fluid was measured in counts per minute (cpm), determined every 30 minutes for up to four hours in the luminal or serosal presence or absence (control) of $10 \mathrm{nM} \mathrm{BFT}-2$ $(n=5)$.

\section{MORPHOMETRY}

After the Ussing chamber experiments, tissues were processed for light microscopy. Mucosal damage of surface and crypt epithelium was assessed by a histopathologist (RS), who performed morphometry on coded, paraffin wax embedded, haematoxylin and eosin stained slides as previously described. ${ }^{27} 2830$ The histopathologist was not informed about the experimental conditions to which the tissues had been exposed. The surface area of each tissue sample was $1 \times 1 \mathrm{~cm}$. Morphometry was performed on nine vertical sections from different locations, each representing the total height and length $(1 \mathrm{~cm})$ of the mucosal preparation. Thus a total length of $8-9 \mathrm{~cm}$ of mucosal surface was examined for each tissue. A Leitz Diaplan research microscope (Wild Leitz Ltd, Heerbrugg, Switzerland; objective magnification, $\times 4, \times 6.3, \times 16, \times 25, \times 40$; ocular magnification, $\times 12.5$ ), a Panasonic colour CCD videocamera (model WV-CD 130/G, Matshushita Com. Ind. Co. Ltd, Japan) an analog/digital monitor screen (model PVM1271Q, superfine pitch, Sony, Japan), a personal computer (IBM-PS/2, model PS2; IBM, Armonk, New York, USA), extended by insertion of a frame grabber (ITI PCVision plus board; Imaging Technology Corp., Woburn, Massachusetts, USA), and a graphic tablet (Summasketch plus 12 in $\times 12$ in MM 1201; Summagraphics Corp., Fairfield, Connecticut, USA) were used. Downloading MIPSY (the micro based image processing system), real time morphometry was performed. The extent of damaged crypt or surface epithelium was separately measured in $\mu \mathrm{m}$ and expressed as percentage of total surface or crypt epithelium.

Histological criteria for epithelial damage were: reduced staining intensity of epithelial cells, condensation, fragmentation and dissolution of the nucleus, cell disruption, formation of subepithelial blebs, and lifting of cells from the basal lamina. ${ }^{27}{ }^{28}{ }^{30}$ No tissue strip used in these experiments showed histological criteria of malignancy or inflammation.

\section{FLUORESCENT MICROSCOPY}

At the end of the Ussing chamber experiments tissues were processed for fluorescent microscopy. Fluorescent staining of $\mathrm{F}$ actin was performed using fluorescein isothiocyanate (FITC) labelled phalloidin (Molecular Probes, Inc.) on fresh frozen tissues. Sections $(4 \mu \mathrm{m})$ were fixed in $2 \%$ paraformaldehyde, $0.01 \mathrm{M}$ sodium periodate, $0.075 \mathrm{M}$ lysine, and $0.37 \mathrm{M}$ sodium phosphate ( $\mathrm{pH} 7.4)$, washed in Tris buffered saline (TBS, $\mathrm{pH}$ 7.5) and incubated 


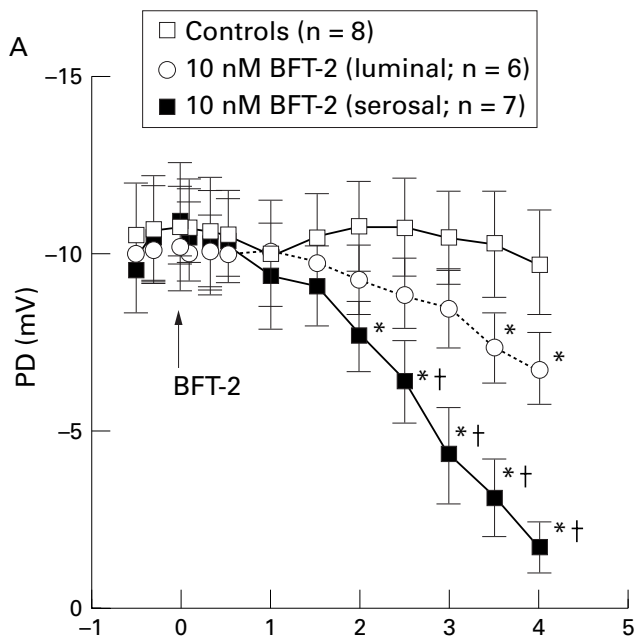

B

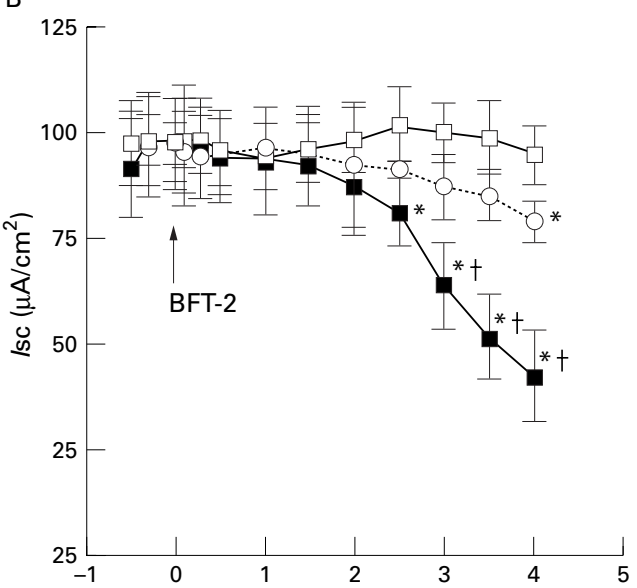

C

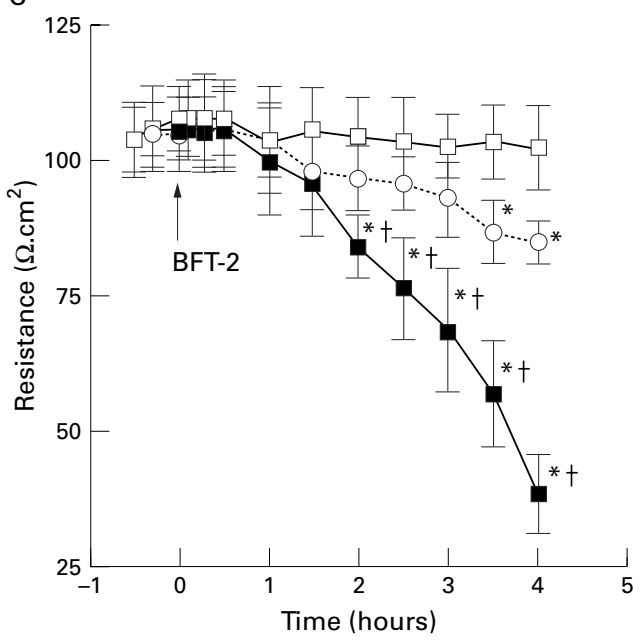

Figure 1 Time course of the effect of BFT-2 on (A) colonic potential difference (PD), (B) short circuit current (Isc), and (C) resistance. Values represent mean (SEM);n $=$ number of experiments. ${ }^{*} p<0.05$ versus controls; $t p<0.05$ versus luminal BFT.

for one hour at room temperature in TBS containing $1 \%$ normal donkey serum and 3\% bovine serum albumin (TBS block). Sections were then incubated for one hour at room temperature in FITC-phalloidin (Sigma; $10 \mu \mathrm{g} / \mathrm{ml}$ in TBS block). Subsequently, slides were mounted with glycerol:PBS (1:9) and $n$-propyl-gallate $(1 \mathrm{mg} / \mathrm{ml})$ and examined and photographed using a laser confocal microscope (Carl Zeiss Inc., Thornwood, New York, USA). For each experimental condition five tissues derived from five individual specimens were investigated.

\section{STATISTICS}

All data were expressed as mean (SEM) and probabilities were regarded as significant if they reached a $95 \%$ level of confidence $(p<0.05)$ using the Student's $t$ test for paired and unpaired observations. The statistical test compared morphometric, electrophysiological (PD, Isc, R), and permeability values of controls versus experimental tissues at defined time points and baseline values of $\mathrm{PD}$, Isc, and $R$ versus values obtained after one and four hours of toxin exposure.

\section{Results}

EFFECT OF TOXIN ON ELECTROPHYSIOLOGY

The effects of BFT-2 on colonic electrophysiology were compared using $\mathrm{PD}$, Isc, and $\mathrm{R}$. BFT-2 caused time dependent changes in electrophysiological parameters which were more notable when the toxin $(10 \mathrm{nM})$ was applied on the serosal aspect of tissues versus the luminal side (fig 1). Serosal application of BFT-2 caused a PD increase towards less negative values and $R$ decrease which became statistically significant two hours after toxin exposure $(\mathrm{p}<0.05$ versus controls). PD and $\mathrm{R}$ values continued to increase and decrease, respectively, until the end of the four hour observation period. Serosal BFT-2 also caused a decline in Isc which became statistically significant 2.5 hours after toxin exposure $(p<0.05$ versus controls). Thereafter Isc continued to decrease until the end of the incubation period (fig 1). In contrast, luminal exposure of colonic mucosa to BFT- 2 caused a less steep change in electrophysiological parameters which became significantly different from controls only after 3.5 hours of continuous toxin exposure for PD and R and after four hours for Isc ( $<<0.05$; fig 1$)$.

The effect of different doses of BFT-2 was tested on electrophysiological parameters. As shown in table 1 and fig 2, PD, Isc, and R remained stable for up to four hours in control strips incubated with buffer alone. In contrast, serosal exposure of mucosal strips to 10,5 , and $2.5 \mathrm{nM} \mathrm{BFT}-2$ for four hours caused a significant, dose dependent PD increase and Isc and $\mathrm{R}$ decrease as compared with buffer exposed tissues as well as to the baseline value of the same colonic strip prior to toxin exposure $(p<0.05)$. Incubation of tissues with $1.25 \mathrm{nM}$ serosal BFT-2 did not affect colonic electrophysiology. On a molar basis, serosal BFT-2 was approximately three to four times more potent than luminal BFT-2 in producing a similar drop in resistance (fig 2).

\section{Permeability to ${ }^{3} \mathrm{H}$-mannitol}

The effect of luminal or serosal administration of $32 \mathrm{nM} \mathrm{BFT}-2$ on serosal to mucosal permeability to ${ }^{3} \mathrm{H}$-mannitol was studied. As shown in fig 3, continuous serosal or luminal administration of $10 \mathrm{nM} \mathrm{BFT}-2$ for four hours caused a 
Table 1 Effect of BFT-2 on electrophysiology of human colonic mucosa

\begin{tabular}{|c|c|c|c|c|c|c|}
\hline & \multirow[b]{2}{*}{ Controls $(n=8)$} & \multicolumn{5}{|l|}{$B F T-2$} \\
\hline & & $\begin{array}{l}\text { Luminal } 10 \mathrm{nM} \\
(\mathrm{n}=6)\end{array}$ & $\begin{array}{l}\text { Serosal } 10 n M \\
(n=7)\end{array}$ & $\begin{array}{l}\text { Serosal } 5 n M \\
(n=6)\end{array}$ & $\begin{array}{l}\text { Serosal } 2.5 n M \\
(n=5)\end{array}$ & $\begin{array}{l}\text { Serosal } 1.25 n M \\
(n=5)\end{array}$ \\
\hline \multicolumn{7}{|l|}{$\mathrm{PD}(\mathrm{mV})$} \\
\hline Baseline & $-10.8(1.8)$ & $-10.2(0.5)$ & $-10.9(1.0)$ & $-9.6(1.6)$ & $-9.5(1.1)$ & $-9.8(1.2)$ \\
\hline $1 \mathrm{~h}$ & $-10.0(1.5)$ & $-10.1(0.8)$ & $-9.4(1.5)$ & $-10.1(0.9)$ & $-9.4(0.9)$ & $-10.3(1.5)$ \\
\hline $4 \mathrm{~h}$ & $-9.8(1.5)$ & $-6.8(1.0)^{\star} \dagger$ & $-1.7(0.7)^{\star} \dagger$ & $-4.6(0.9)^{\star} \dagger$ & $-7.1(0.5)^{\star} \dagger$ & $-10.4(1.1)$ \\
\hline \multicolumn{7}{|l|}{ Isc $\left(\mu \mathrm{A} / \mathrm{cm}^{2}\right)$} \\
\hline Baseline & $97(5)$ & $97(11)$ & $98(10)$ & $92(10)$ & $89(4)$ & $93(7)$ \\
\hline $1 \mathrm{~h}$ & $94(8)$ & $96(10)$ & $93(13)$ & $95(8)$ & $93(7)$ & $98(11)$ \\
\hline $4 \mathrm{~h}$ & $95(7)$ & $79(5)^{\star} \dagger$ & $43(11)^{\star}+$ & $69(9)^{\star}+$ & $77(5)^{\star}+$ & $97(9)$ \\
\hline \multicolumn{7}{|c|}{$\mathrm{R}\left(\mathrm{Ohm} \cdot \mathrm{cm}^{2}\right)$} \\
\hline Baseline & $108(6)$ & $105(7)$ & $106(6)$ & $104(6)$ & $106(6)$ & $104(8)$ \\
\hline $1 \mathrm{~h}$ & $104(10)$ & $104(7)$ & $100(10)$ & $105(6)$ & $103(5)$ & $106(10)$ \\
\hline $4 \mathrm{~h}$ & $103(8)$ & $85(4)^{\star} \dagger$ & $38(7)^{\star} \dagger$ & $64(10)^{\star} \dagger$ & $88(5)^{\star}+$ & $102(7)$ \\
\hline
\end{tabular}

Results expressed as mean (SEM); $\mathrm{n}=$ number of experiments.

${ }^{\star} \mathrm{p}<0.05$ versus controls; $\uparrow \mathrm{p}<0.05$ compared with baseline obtained in the same tissue before exposure to toxin.

4.7-fold and 2.2-fold increase in permeability, respectively, when compared with controls $(\mathrm{p}<0.01)$. Permeability changes became statistically significant after two and 3.5 hours after serosal and luminal exposure to BFT-2, respectively, when compared with controls $(\mathrm{p}<0.05)$.

EFFECT OF TOXIN ON HISTOLOGY

Histological examination of colonic strips incubated with buffer alone for five hours showed normal colonic architecture (fig 4A). Serosal and luminal administration of BFT-2 caused similar morphological changes in crypt and surface epithelium which were time and dose dependent. Following 2.5 hours of serosal incubation with $10 \mathrm{nM}$ BFT-2, histology revealed damage of cells at the crypt base whereas the surface epithelium remained intact (fig 4B). However, after four hours severe damage of both crypt and surface colonocytes was observed (fig 4C). BFT-2 caused cell rounding and detachment of crypt enterocytes into the crypt lumen (long arrows in fig 4D). In surface epithelial cells BFT induced apical localisation of the pyknotic nucleus, and cytoplasmic elongation and luminal protrusion

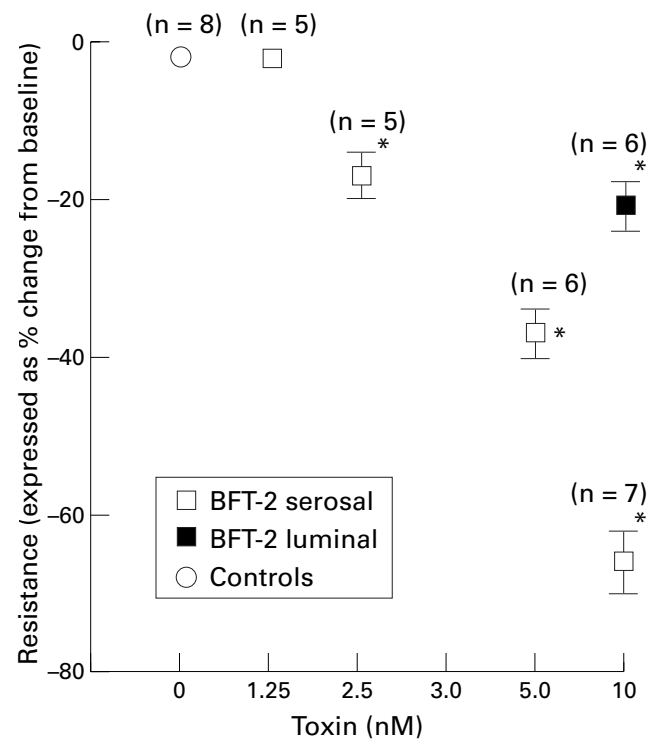

Figure 2 Dose dependent effect of BFT-2 on colonic resistance. Values represent mean (SEM); $n=$ number of experiments. ${ }^{\star} p<0.05$ versus controls. of the enterocyte (arrowheads in fig 4D). Injured enterocytes were separated from neighbouring cells and detached into the lumen. Furthermore, serosal BFT-2 caused loosening and disruption of the basal lamina (broad arrows in fig 4D). Luminal addition of $10 \mathrm{nM}$ BFT-2 for four hours was less effective in damaging surface and crypt epithelium and did not cause alterations of the basal lamina (not shown).

BFT-2 induced morphological damage of crypt and surface epithelium was dose dependent (fig 5). Serosal administration of $10 \mathrm{nM}$ BFT-2 was approximately seven and three times more potent at damaging crypt and surface epithelium, respectively, when compared with luminal BFT-2.

\section{DISTRIBUTION OF F ACTIN}

Previous studies showed that BFT-2 causes alterations in enterocyte $\mathrm{F}$ actin. ${ }^{20}$ Thus, the effect of BFT-2 on F actin distribution in human colonic mucosa was examined, using fluorescent phalloidin to detect $\mathrm{F}$ actin. As shown in fig 6A, control cells had a polygonal shape with $\mathrm{F}$ actin distributed in the peripheral actin ring. Furthermore, control enterocytes showed intense $\mathrm{F}$ actin staining of the apical brush border membrane (arrowheads in fig 6A). As shown in fig 6B, serosal exposure to 10

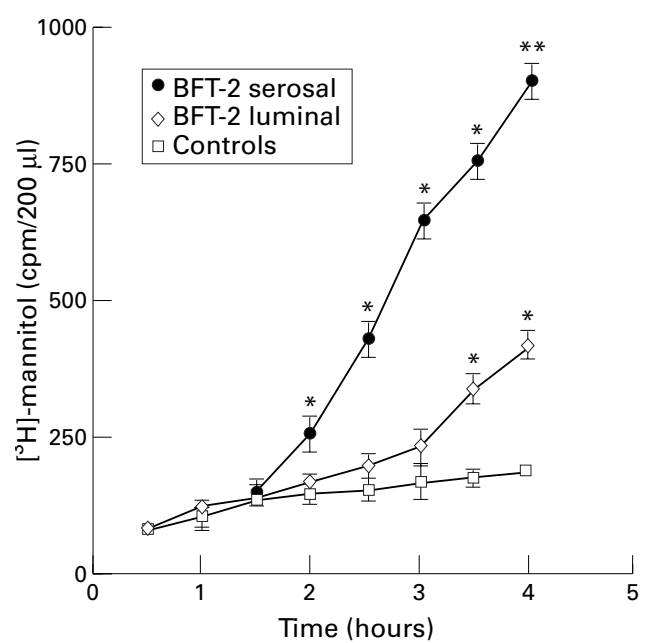

Figure 3 Effect of BFT-2 on colonic ${ }^{3} \mathrm{H}$-mannitol permeability. Values are mean (SEM) of five experiments performed in triplicate. ${ }^{\star} p<0.05,{ }^{\star *} p<0.01$ versus controls. 

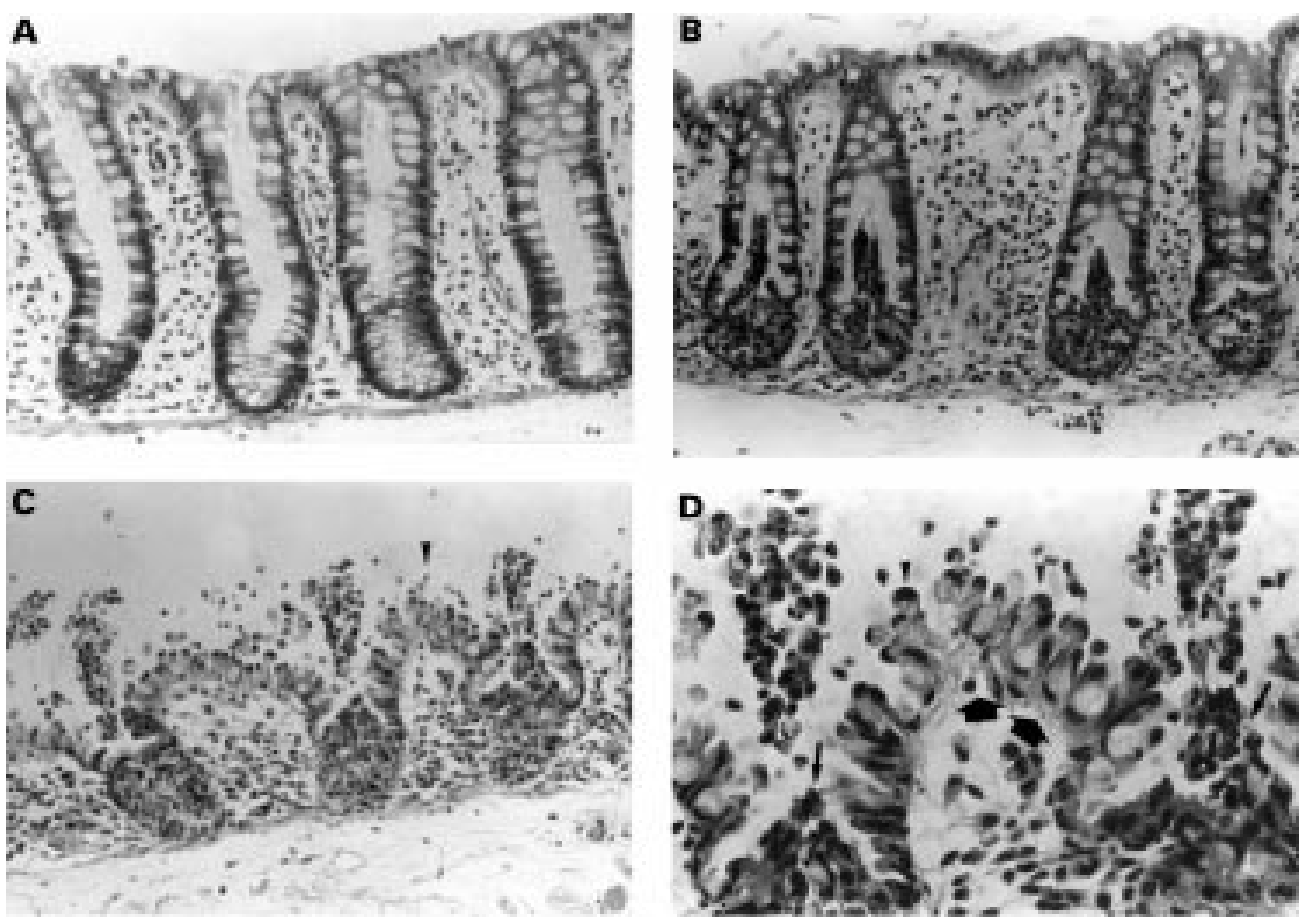

Figure 4 Morphological effect of BFT-2 on human colonic mucosa. Human colonic mucosal sheets were incubated with either buffer alone for four hours $(A)$ or serosal buffer containing $10 \mathrm{nM} B F T-2$ for 2.5 hours $(B)$ or four hours $(C, D)$. At the end of the incubation period sheets were fixed in formalin and processed for light microscopy. (A) Control tissue appears normal and epithelial cells form a continuous sheet over the lamina propria. (B) The mucosal sheet shows disruption of crypt epithelium whereas the surface epithelium remains intact. (C) The mucosal sheet shows disruption of surface and crypt epithelium. The arrowhead marks an area shown at higher magnification in (D) which shows rounding and detachment of crypt enterocytes into the lumen (long arrows). Surface colonocytes show cytoplasmic elongation and apical localisation of the pyknotic nucleus (arrowheads). Note loosening of the basal lamina (broad arrows). Original magnification $\times 140(A, B) ; \times 80(C) ; \times 420(D)$.

nM BFT-2 for two hours resulted in an overall reduction in $\mathrm{F}$ actin staining intensity and disruptions of the $\mathrm{F}$ actin ring (arrowheads in fig $6 \mathrm{~B})$. After four hours of serosal exposure to 10 $\mathrm{nM}$ BFT-2, staining of the enterocyte $\mathrm{F}$ actin ring was nearly abolished (fig 6C,D). However, some $\mathrm{F}$ actin staining remained in the brush border of damaged enterocytes (EC in fig 6D) or in exfoliated enterocytes (arrowheads in fig $6 \mathrm{D})$. Effects on enterocyte $\mathrm{F}$ actin were similar, but less profound after luminal administration of BFT-2 (10 nM) (not shown). In tissue

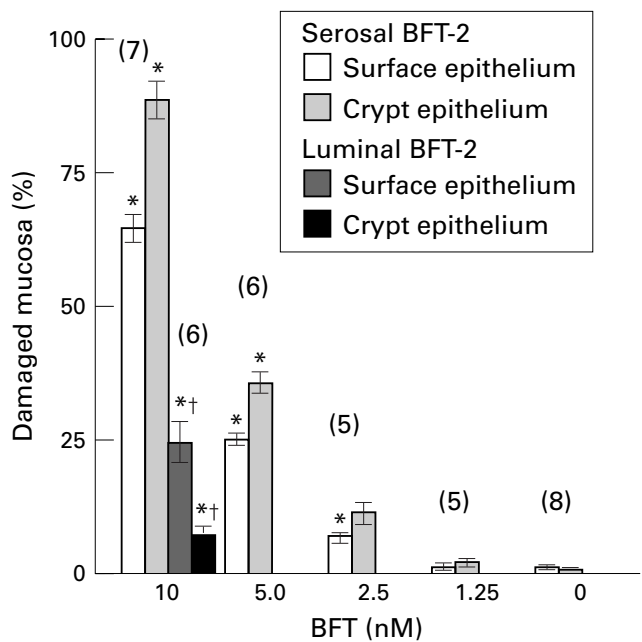

Figure 5 Morphometric analysis of colonic epithelial cell damage caused by BFT-2. Values are mean (SEM). The number of experiments is given in brackets. ${ }^{\star} p<0.05$ versus controls; $t p<0.05$ versus serosal $10 \mathrm{nM} \mathrm{BFT-2.}$ exposed to toxin and used for staining experiments (fig 6B-D) PD increased and $\mathrm{R}$ and Isc decreased during Ussing chamber experiments, while control tissues (fig 6A) exhibited stable electrophysiological values throughout the experiment.

\section{Discussion}

Purified BFT-2 caused electrophysiological alterations, increased epithelial permeability to mannitol, and morphological damage to human colonic mucosa.

The BFT-2 induced morphological damage of colonocytes was characterised by rounding and exfoliation, which was paralleled by an increase in transepithelial ${ }^{3} \mathrm{H}$-mannitol flux, a sensitive measure of tight junction permeability. Myers and colleagues ${ }^{89}$ showed that luminal administration of $B$ fragilis causes rounding and exfoliation of surface and crypt epithelial cells of rabbit colon in vivo. Weikel and colleagues ${ }^{23}$ showed that culture medium of ETBF induces cell rounding and loss of cell to cell contact in subconfluent T84, Caco2, and HT 29/C1 cells. Similar morphological changes in HT 29 or HT 29/C1 cells in vitro were evident after treatment with purified BFT-1 or BFT-2. ${ }^{14} 2024$ We have recently observed that BFT- 1 or BFT- 2 causes dose dependent disruptions of tight junctions and zonula adherens in T84 cell monolayers. ${ }^{25}$ Furthermore, Obiso and colleagues ${ }^{26}$ recently showed that BFT-1 causes a decrease in the immunofluorescent staining intensity of the tight junction protein $\mathrm{ZO}-1$ in MDCK cells in 

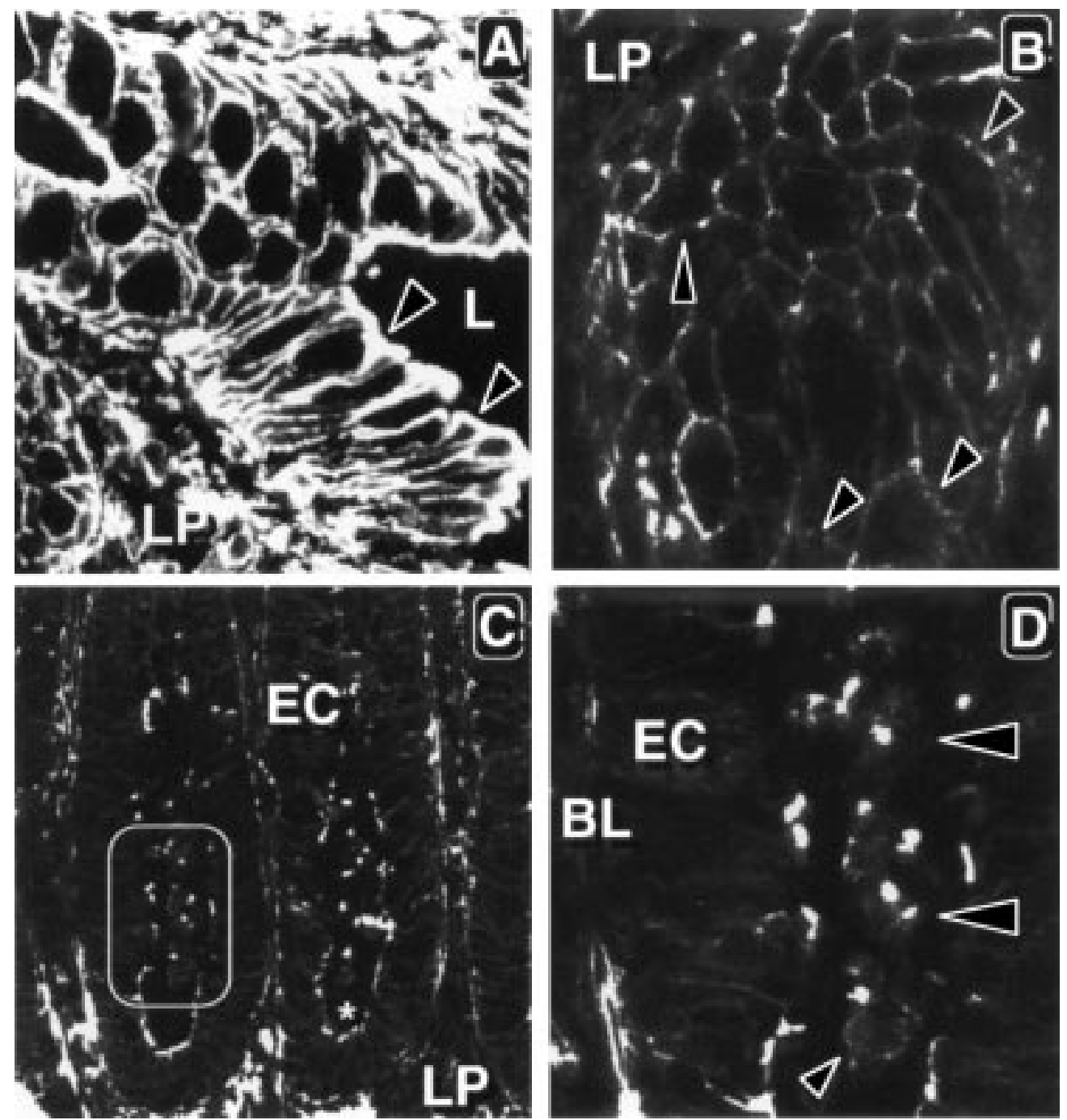

Figure 6 Effect of BFT-2 on cellular $F$ actin. Fluorescent photomicrograph of human colonic mucosal sheet incubated with buffer alone $(A)$ or serosal buffer containing $10 \mathrm{nM} B F T-2$ for two hours $(B)$ or four hours $(C, D)$. Samples were fixed and fresh frozen sections cut perpendicularly $(B)$ or vertically $(A, C, D)$ to the long axis of surface cells. $(A)$ Control cells had a polygonal shape with $F$ actin distributed in the peripheral actin ring. Arrowheads mark intense $F$ actin staining of the apical brush border. L, lumen; LP, lamina propria. (B) There was an overall reduction in F actin staining intensity and disruption of the $F$ actin ring (arrowheads). (C) There was an overall reduction in $F$ actin staining in epithelial cells (EC). The rectangle marks a crypt shown at higher magnification in (D), and the asterisk marks the basal lumen of the crypt. (D) Staining of the enterocyte $F$ actin ring was nearly abolished. Some $F$ actin staining remained in the brush border of damaged enterocytes $(E C)$ or in exfoliated enterocytes (arrowheads). BL, basal lamina. Original magnification $\times 400$ ( A, $B) ; \times 200(C) ; \times 480(D)$.

vitro. In addition, Moncrief and colleagues ${ }^{17}$ showed that BFT-1 is a metalloprotease which hydrolyses actin, fibrinogen, and collagen in vitro. Therefore, in addition to loosening cell to cell contacts, digestion of the basal lamina might contribute to increased damage after serosal administration of BFT-2. Taken together, these results indicate that the interaction of BFTs with epithelial cells leads to disruption of intercellular junctions and/or cell-basal laminal binding, resulting in increased paracellular permeability.

Serosal BFT-2 administration was more potent than luminal administration at inducing electrophysiological, permeability, and morphological changes. In agreement with this finding, in vitro studies using polarised intestinal ${ }^{22}{ }^{24-26}$ and non-intestinal epithelial cell lines $^{26}$ have shown that BFT-1 and BFT-2 reduce monolayer resistance and that this decline in resistance is polar, occurring more

quickly with application of the toxin to the basolateral, rather than the apical surface of the monolayers. Taken together, the results of the present and recent studies ${ }^{22} 24-26$ indicate that BFT-2 may act via a receptor(s) or a target molecule localised on both apical and basolateral membranes of surface and crypt enterocytes. We speculate that the polarity dependency of BFT-2 induced biological effects may be due to either easier access of this toxin to target molecule(s) or receptors localised on the basolateral side of the epithelial cells, and/or that BFT-2 may also interact with subepithelial inflammatory cells, nerve cells or fibroblasts. Release of proinflammatory cytokines from these cells may contribute to the biological responses following BFT-2 administration.

Our results did not show electrophysiological changes indicative of BFT-2 induced secretion. In contrast, Chambers and colleagues ${ }^{25}$ found that BFT-2 induces an early increase in 
Isc in T84 cell monolayers that was attributable to chloride secretion. The discrepancy between the results presented here and those of Chambers et al may reflect differences between a malignant cell line used by Chambers et al and the normal colonic mucosal strips used in this study.

As shown by confocal microscopy of FITCphalloidin stained sections, BFT-2 almost completely abolished $\mathrm{F}$ actin staining in damaged enterocytes, except for some intracellular and apical condensations of $\mathrm{F}$ actin. Interestingly, this result differs from the effects of BFT on F actin in intestinal epithelial cells in vitro. In intact HT 29 or HT 29/C1 cells BFT seems to stimulate actin rearrangement without cleavage of $\mathrm{F}$ actin in vitro. ${ }^{182024}$ Furthermore Saidi and colleagues ${ }^{20}$ showed that incubation with BFT-1 for up to 24 hours did not alter net actin content in HT 29/C1 cells in vitro. However, an increased $\mathrm{F}$ action staining intensity could be observed on the periphery of HT $29 / \mathrm{Cl}^{19}{ }^{20}$ and HT $29^{18}$ cells after two to three hours of with incubation with BFT. Modulation of $\mathrm{F}$ actin distribution in intestinal epithelial cells is not unique to $B$ fragilis. For example, Clostridium difficile toxins A and $\mathrm{B}$ cause disruption and condensation of $\mathrm{F}$ actin without completely abolishing $\mathrm{F}$ actin staining in intestinal epithelial cells ${ }^{27}$ and fibroblasts. ${ }^{31-33}$ The zonula occludens toxin of Vibrio cholerae $e^{34}$ and heat stable enterotoxin of Escherichia coli $^{35}$ were also shown to cause rearrangement of $\mathrm{F}$ actin in rabbit ileum and T84 cell monolayers, respectively.

In summary, the present study shows that BFT-2 increases human colonic permeability and damages colonic epithelial cells in vitro. These results may be relevant to the pathophysiological mechanism by which $B$ fragilis causes diarrhoea and intestinal inflammation in vivo.

This study was supported by grants from the Jubiläumsfonds der Österreichischen Nationalbank, the Anton DreherGedächtnisschenkung des medizinischen Dekanates der Universität Wien, and, in part, by NIH grant DK 45496 to CS. MR was supported by a grant from the Max Kade Foundation, New York, and M L and IC were supported by a Research Carrier Development Award from the Crohn's and Colitis Foundation of America, Inc. We thank Dr Shaoquang Wu for purification of the BFT-2 used in these studies and Ingrid Hammer for her expert technical support.

1 Border MM, Firehammer BD, Shoop DS, et al. Isolation of Bacteroides fragilis from the feces of diarrhetic calves and lambs. F Clin Microbiol 1985;21:472-3.

2 Collins JE, Bergeland ME, Myers LL, et al. Exfoliating colitis associated with enterotoxigenic Bacteroides fragilis in a piglet. 7 Vet Diagn Invest 1989:1:349-51.

3 Duimstra JR, Myers LL, Collins JE, et al. Enterovirulence of enterotoxigenic Bacteroides fragilis in gnotobiotic pigs. Vet Pathol 1991;28:514-18.

4 Myers LL, Firehammer BD, Shoop DS, et al. Bacteroides fragilis: a possible cause of acute diarrheal disease in newfragilis: a possible cause of acute diarreal dise

5 Myers LL, Shoop DS, Firehammer BD, et al. Association of Myers LL, Shoop DS, Firehammer BD, et al. Association of enterotoxigenic Bacteroides fragilis with
in calves. F Infect Dis 1985;152:1344-7.

in calves. F Infect Dis 1985;152:1344-7.
6 Myers LL, Shoop DS. Association of enterotoxigenic Bacteroides fragilis with diarrheal disease in young pigs. Am F Vet Res 1987;48:774-5.

7 Myers LL, Shoop DS, Byars TB. Diarrhea associated with enterotoxigenic Bacteroides fragilis in foals. Am F Vet Res 1987;48:1565-7.
8 Myers LL, Shoop DS, Collins JE. Rabbit model to evaluate enterovirulence of Bacteroides fragilis. 7 Clin Microbiol 1990;28:1658-60

9 Myers LL, Shoop DS, Collins JE, et al. Diarrheal disease caused by enterotoxigenic Bacteroides fragilis in infant rabbits. F Clin Microbiol 1989;27:2025-30.

10 Myers LL, Shoop DS, Stackhouse LL, et al. Isolation of enterotoxigenic Bacteroides fragilis from humans with diarrhea. F Clin Microbiol 1987;25:2330-3.

11 Pantosti A, Piersimoni C, Perissi G. Detection of Bacterioides fragilis enterotoxin in the feces of a child with diarrhea. Clin Infect Dis 1994;19:809-10.

12 Sack RB, Myers LL, Almeido-Hill J, et al. Enterotoxigenic Bacteroides fragilis: epidemiologic studies of its role as a human diarrheal pathogen. F Diarrhoeal Dis Res 1992;10:49.

13 Sack RB, Albert MJ, Alam K, et al. Isolation of enterotoxigenic Bacteroides fragilis from Bangladeshi children with diarrhea. 7 Clin Microbiol 1994;32:960-3.

14 Van Tassell RL, Lyerly DM, Wilkins TD. Purification and characterization of an enterotoxin from Bacteroides fragilis. Infect Immun 1992;60:1343-50.

15 Obiso RJ Jr, Lyerly DM, Van Tassel RL, et al. Proteolytic activity of the Bacteroides fragilis enterotoxin causes fluid secretion and intestinal damage in vivo. Infect Immun 1995; 63:3820-6.

16 Franco AA, Mundy LM, Trucksis M, et al. Cloning and characterization of the Bacteroides fragilis metalloprotease toxin gene. Infect Immun 1997;65:1007-13.

17 Moncrief JS, Obiso RJ Jr, Barroso LA, et al. The enterotoxin of Bacteroides fragilis is a metalloprotease. Infect Immun 1995;63:175-81.

18 Donelli G, Fabbri A, Fiorentini C. Bacteroides fragilis enterotoxin induces cytoskeletal changes and surface blebbing in HT 29 cells. Infect Immun 1996;64:113-19.

19 Koshy SS, Montrose MH, Sears CL. Human intestinal epithelial cells swell and demonstrate actin rearrangement in response to the metalloprotease toxin of Bacteroides fragilis. Infect Immun 1996;64:5022-8.

20 Saidi RF, Jaeger K, Montrose $\mathrm{MH}$, et al. Bacteroides fragilis toxin alters the actin cytoskeleton of HT $29 / \mathrm{C} 1$ cells in vitro qualitatively but not quantitatively. Cell Motil Cytoskeleton 1997;37:159-65.

21 Saidi RF, Sears CL. Bacteroides fragilis toxin rapidly intoxicates human intestinal epithelial cells (HT 29/C1) in vitro. Infect Immun 1996;64:5029-34.

22 Sears CL, Myers LL, Lazenby A, et al. Enterotoxigenic Bacteroides fragilis. Clin Infect Dis 1995;20(suppl 2): S142-8

23 Weikel CS, Grieco FD, Reuben J, et al. Human colonic epithelial cells, HT 29/C1, treated with crude Bacteroides fragilis enterotoxin dramatically alter their morphology. Infect Immun 1992;60:321-7.

24 Wells CL, van de Westerlo EMA, Jechorek RP, et al. Bacteroides fragilis enterotoxin modulates epithelial permeability and bacterial internalization by HT 29 enterocytes. Gastroenterology 1996;110:1429-37.

25 Chambers FG, Koshy SS, Saidi RF, et al. Bacteroides fragilis toxin exhibits polar activity on monolayers of human intestinal epithelial cells (T84 cells) in vitro. Infect Immun 1997;65:3561-70.

26 Obiso RJ Jr, Azghani AO, Wilkins TD. The Bacteroides fragilis toxin fragilysin disrupts the paracellular barrier of epithelial cells. Infect Immun 1997;65:1431-9.

27 Riegler M, Sedivy R, Pothoulakis C, et al. Clostridium difficile toxin B is more potent than toxin A in damaging
human colonic epithelium in vitro. 7 Clin Invest 1995;95: 2004-11.

28 Feil W, Lacy E, Wong YM, et al. Rapid epithelial restitution of the human and rabbit colonic mucosa. Gastroenterology 1989;97:685-701

29 Grass GM, Sweetana SA. In vitro measurements of gastrointestinal tissue permeability using a new diffusion cell. Pharm Res 1988;6:372-6.

30 Riegler M, Sedivy R, Sogukoglu T, et al. Epidermal growth factor promotes rapid response to epithelial injury in rabbit duodenum in vitro. Gastroenterology 1996;111:28-36.

31 Dillon ST, Rubin EJ, Yakubovich $M$, et al. Involvement of Ras-related rho proteins in the mechanism of action of Clostridium difficile toxin $\mathrm{A}$ and toxin B. Infect Immun 1995;63:1421-6.

32 Just I, Fritz G, Aktories K, et al. Clostridium difficile toxin B acts on the GTP-binding protein rho. $f$ Biol Chem 1994;269:10706-12.

33 Just I, Selzer J, Wilm M, et al. Glucosylation of rho proteins by Clostridium difficile toxin B. Nature 1995;375:500-3.

34 Fasano A, Fiorentini C, Donelli G, et al. Zonula occludens toxin modulates tight junctions through protein kinase $\mathrm{C}$-dependent actin reorganization, in vitro. $\mathcal{F}$ Clin Invest 1995;96:710-20.

35 Matthews JB, Awtrey CS, Thompson $\mathrm{R}$, et al. $\mathrm{Na}^{+}-\mathrm{K}^{+}-2 \mathrm{Cl}$ cotransporter and $\mathrm{Cl}^{-}$secretion evoked by heat-stable enterotoxin is microfilament dependent in T84 cells. Am F Physiol 1993;265:G370-8. 